\title{
Abstracts
}

\section{Medicine in Society}

\section{J. Grimley Evans}

Daniel Callahan, 'Aging and the ends of medicine'. Annals of the New York Academy of Medicine, $53^{\circ}$ (1988), I 25-1 $3^{2}$.

Daniel Callahan is the Director of The Hastings Centre, which has an important influence on public opinion on issues of medical ethics in North America. This paper was presented in the context of an AngloAmerican dialogue on medical ethics held in New York in 1987.

Over the last two decades, the political activism of retired people in the USA, and popular emphasis on old age as a time of liberation rather than decline, has led to a sizeable increase in the funds provided, directly and indirectly, to health services used by elderly people. There is concern that these funds have to some extent been generated by transfer from other traditionally disadvantaged groups, particularly among the young of ethnic minorities. This is producing an anti-elderly backlash among the advocacy groups for the losers. There is no evidence that a similar transfer has taken place in the United Kingdom but we may expect such claims to be made.

Which groups of the community should lose or gain when resources have to be divided up are decisions that politicians are paid to make. Politicians, no less than anyone else, value their privileges more than their responsibilities and are glad to see political decisions dressed up as if they were ethical (in the USA) or economic (in the UK). This paper is a glimpse of how contemporary American ageism seeks to justify itself in ethical terms.

Dissertations on ethics should start with a statement of the author's ideological premises and a definition of the problem to be addressed. We are left in the dark about Callahan's ideology but his implicit exemplification of the problem is to report a $\$ 200$,000 liver transplant operation carried out on a 76 -year-old woman in 1986 . He continues by setting out the large cost in the United States of providing medical care for the older population, and seems to define the ethical issue as lying in the possible 'harmful' effects it may produce through 'the economic burdens it will impose on younger age groups'. His solution is to propose that curative medicine should be withheld from people who have outlived their 'natural lifespan'. 'The future goal of 
medicine in the care of the aged', Callahan asserts, 'should be that of improving the quality of their life, not in seeking ways to extend that life'.

Unfortunately he does not tell us how to define or recognise a natural life-span. In some parts of the paper he seems to be adopting an existential approach, with the idea that we all reach a time when we have either achieved our major objectives or must recognise that we are never going to, and when our physical and mental powers are declining to the point where old interests begin to bore and the new ceases to entice. Unfortunately it is clear elsewhere in the paper that Callahan is not embracing this individualized view, in which, presumably, the end of a natural life-span might lie anywhere between puberty and infinity. He notes that 'people will differ on what they might count as a natural life-span', but then immediately goes on to say that an appropriate range 'for social policy purposes' would need to be defined, and adds, 'my own view is that it can now be achieved by the late seventies or early eighties'.

Clearly the concept of natural life-span is being used in two quite different ways and there are other places in this paper where such ambiguities seem to be absorbed in a way that seems less than philosophically rigorous. He states, for example, that 'the use of age as a principle for the allocation of resources can be perfectly valid, both a necessary and legitimate basis for providing health care to the elderly'. The words 'valid', 'necessary' and 'legitimate' in this sentence seem chosen to provoke warm and supportive ideas in the unwary reader unless he or she pauses to wonder what exactly they are supposed to mean. How would you 'validate' the use of age as a principle for resource allocation? In what way is it a 'necessary' basis and what on earth does 'legitimate' mean in this context? Callahan makes no attempt to tell us.

An important issue behind what Callahan has to say is the undoubted fact that high-technology curative medicine is sometimes over-used in the care of elderly people in the United States. As is well recognised, one approach to this would be to control the abuses of litigation so that good sense and compassion can be reinstated at the bedside. Another would be to examine the structure of financial incentives built into an entrepreneurial system of health care. Callahan notes with approval that specialist geriatric services in Britain focus on quality rather than the prolongation of life. He is wrong, however, in assuming that this precludes the use of high technology treatment or should do so. Rather, the British ideal is, by careful appraisal of each patient as an individual, to use expensive treatment for those elderly people who will enjoy any 
'extra' years it can produce for them. To most specialist geriatricians in Britain, the idea that an elderly person should be precluded from expensive treatment on the basis of age alone would certainly be utterly abhorrent. No doubt, even in the United States it would only be the poor elderly whose natural life-spans would be defined. The problem is that, although age is a variable that tells us a great deal about the average outcome from the medical treatment of groups of people, it tells us little or nothing about the actual outcome of individuals within those groups. It is surely the welfare and rights of individuals that Anglo-American civilisation is distinctively concerned to promote.

Radcliffe Infirmary, University of Oxford

Older Women

Sheila Peace

Terry Arendell and Carroll Estes, 'Unsettled future: older women: economics and health'. Feminist Siudies, 1, I (1987), 3-25.

The importance of this paper by Arendell and Estes lies in the analytical framework offered by the authors which seeks to combine a structural analysis of the disadvantaged position of older women in the United States with a life-course perspective. In doing so they are able to demonstrate that disadvantage 'is not a result of old age, but is a result of life-long patterns of socio-economic and gender stratification in the larger society'. They argue that, because of deep-seated inequalities, service solutions to the needs of older women, while vitally important, will not provide all the answers. They suggest that what are needed are 'broad based solutions that address sex, race and age discrimination in the labour market, unequal pay for jobs of comparable worth, and the invidious quality of income security programs for older women that are predicated on inaccurate assumptions, wage discrimination, and a life time of devalued caregiving work'.

To support this argument, their analysis centres on the complex interrelationship between the informal sectors (the family) and the formal sectors (the labour market and social policy) of women's lives, which they use to demonstrate how economic status and health status are directly linked. To do this the paper presents a range of interesting 